\title{
DOSSIÊ
}

\section{Ensino Religioso como disciplina curricular: uma breve apresentação de alguns modelos existentes para orientação desse ensino em escolas particulares}

Elaine Costa Honorato ${ }^{1}$

Resumo: Este artigo apresenta questões referentes ao Ensino Religioso como disciplina curricular. Tem como objetivo principal mostrar alguns modelos e propostas desse componente curricular de ensino. $\mathrm{O}$ texto pretende ser uma contribuição instigante para todos os que procuram entender a razão do Ensino Religioso nas escolas bem como refletir e pensar na constituição ideológica do Ensino Religioso. Para realização deste artigo, utilizou-se do método bibliográfico e de autores que trabalham com as temáticas religião e educação, como Passos (2007), Junqueira (2013) e Bowker (2000). Palavras-chave: Ensino Religioso. Proposta curricular. Educação.

Religious Education as a curricular discipline: a brief presentation of some existing models for orientation of this teaching in private schools

Abstract: This article presents questions related to Religious Education as a curricular discipline. Its main objective is to show some models and proposals of this curricular component of teaching. The text intends to be an instigating contribution for all who seek to understand the reason for Religious Education in schools as well as a reflection and thinking on the ideological constitution of Religious Teaching. For the accomplishment of this article, we used the bibliographical method and authors that work with the themes religion and education as Passos (2007), Junqueira (2013) and Bowker (2000).

Keywords: Religious education. Curricular proposal. Education.

Educación Religiosa como disciplina curricular: breve presentación de algunos modelos existentes para la orientación de esta enseñanza en escuelas privadas

Resumen: Este artículo presenta cuestiones referentes a la Educación Religiosa como disciplina curricular. Tiene como objetivo mostrar algunos modelos y propuestas de este componente curricular de enseñanza. El texto pretende ser una contribución provocante para todos los que buscan entender la razón de la Educación Religiosa en las escuelas, así como una reflexionar y pensar en la constitución ideológica de la Edu- 
cación Religiosa. Para la realización de este artículo, se utilizó el método bibliográfico y autores que trabajan con las temáticas religión y educación como Pasos (2007), Junqueira (2013) y Bowker (2000).

Palabras clave: Educación religiosa. Propuesta curricular. Educación.

\section{Introdução}

O componente curricular Ensino Religioso é uma disciplina que apresenta diversas maneiras de aplicabilidade em sala de aula. Dessa forma, este artigo tem como propósito apresentar alguns modelos existentes de Ensino Religioso que são aplicados em escolas privadas. É importante destacar, de antemão, que não se propõe aqui a inexistência de escolas confessionais, uma metodologia adotada nas escolas privadas. Confia-se, ao contrário, que a disciplina Ensino Religioso em escolas privadas mantém projetos importantes, que atende ao desenvolvimento integral dos educandos.

Entretanto, destaca-se que, para realização desses projetos, é preciso, contudo, profissionais preparados e que estejam em constante atualização. Segundo Junqueira (2013, p. 613):

[...] Organizar o cotidiano do ensino religioso no contexto escolar significa assumir esse componente curricular a partir das disciplinas científicas que a estruturam academicamente e contribuem no desenvolvimento das linguagens, no mundo do trabalho, na cultura e na tecnologia, na produção artística, nas atividades desportivas e corporais, na área da saúde e ainda incorporam saberes como os que advêm das formas diversas de exercício da cidadania, dos movimentos sociais, da cultura escolar, da experiência docente, do cotidiano e dos alunos. Os elementos abordados favorecem a relação com os valores sociais, os laços de solidariedade, a superação do preconceito em todas as suas formas ao refletir sobre éthos, especialmente a questão da alteridade.

Por isso, é necessário reconhecer a importância da criação de projetos que utilizem o Ensino Religioso para um bem social, lutando pela cidadania, pelo futuro, sempre tendo em vista o educador como sujeito essencial dessa prática, conforme alguns modelos apresentados neste artigo.

\section{A religião nas propostas pedagógicas}

Toma-se religião, aqui, como conjunto de crenças próprias de um grupo de indivíduos - ou, em casos específicos, de um único indivíduo - em elementos, seres ou representações de ordem sobrenatural, divina ou sagrada. Rituais 
e códigos morais são componentes derivados de uma crença e não podem, sob qualquer hipótese, ser tomados como a religião propriamente dita. Para muitos, contudo, a religião é vista também como fonte fundamental da existência humana e, em casos extremos, como fator único e determinante de importância em suas vidas.

A palavra "religião" é derivada do verbo latino "religare", que significa união, no caso, com o divino, definição que se estende a qualquer forma de aspecto místico e religioso, abrangendo seitas, mitologias e quaisquer outras doutrinas.

Significa quase tudo, porque as religiões dizem respeito à totalidade da vida - e à morte do ser humano. Por milhares de anos a pessoa tem buscado o sentido e a verdade de sua própria natureza e do universo; as religiões, que lidam com a totalidade da vida e morte humanas, resultam dessa busca. Mesmo as ciências naturais eram originalmente religiosas; somente nos últimos trezentos anos religião e ciência se separam como caminhos de conhecimento. Vemos religião hoje como comunidade de pessoas que compartilham práticas e crenças (geralmente em um Deus ou deuses), que se reúnem em construções especiais para o culto ou mediação e que vivenciam o mundo de maneira especial. Sabe-se que a mais de três quartos da população mundial considera-se pertencente a uma religião, independente do pouco ou muito que a pratiquem (BOWKER, 1997, p. 6).

Partindo desse pressuposto, toma-se conhecimento de que hoje em dia, apesar de todo o avanço científico, o fenômeno religioso sobrevive e cresce fazendo com que a grande maioria da humanidade manifeste alguma crença religiosa, direta ou indiretamente.

Assim, a religião continua a promover diversos movimentos humanos, imbricando-se neles, mantendo estatutos políticos e sociais, estendendo-se, até mesmo, e, em alguns casos, sobretudo, às escolas.

Por essa e outras razões, algumas escolas têm como plano curricular o objetivo de oferecer subsídios sobre religião, suas formações, suas doutrinas, seus valores e sua repercussão social. Esse Ensino Religioso tem como intuito contribuir com os projetos pedagógicos e integrar-se como disciplina na grade curricular

[...] como cultivo das disposições necessárias para a vivência coerente de um projeto de vida profundamente humano [...]. Mais que ensinar as respostas desta ou daquela igreja, a Educação Religiosa quer educar ao compromisso, a um ação transformadora. Num país de injustiça estrutural, isso significa prioritariamente atuação junto com os oprimidos em prol da justiça, em nível cada vez mais profundo de conscientização (GRUEN, 1995, p. 186 apud DANTAS, 2004, p. 119). 


\section{Propostas de Ensino Religioso presentes em escolas particulares}

Para muitas escolas particulares, o Ensino Religioso é a área do conhecimento que busca desenvolver a competência religiosa do ser humano na sua formação integral: pessoal, cognitiva, profissional e social.

Toma-se como exemplo a Associação de Escolas Cristãs de Educação por Princípios (AECEP). Essa associação foi fundada em 1997 em São Paulo, a partir da necessidade de novas escolas cristãs que haviam surgido em várias localidades e necessitavam de apoio para o desenvolvimento de propostas educacionais que integrassem o cristianismo.

Hoje, a AECEP conta com escolas de vários Estados do Brasil, promove, entre as escolas associadas, a formação continuada dos profissionais e subsidia o desenvolvimento físico-estrutural e pedagógico. Um dos objetivos principais da instituição é fixar um modelo educacional voltado ao cristianismo para a transformação das nações e à (re)construção de uma nação cristã fundamentada na bíblia.

Se quisermos construir uma nação cristã livre precisamos estabelecer fundamentos bíblicos para a Educação, Governo, Economia e Política. O princípio de semeadura e colheita se aplica para implantarmos a Verdade de Deus nas nações. É num processo gradual, através da Educação Cristã, que as sementes são plantadas e cuidadas, para produzir frutos em todos os aspectos da vida: pessoal, social, político e econômico (AECEP, s/d, s/p).

Segundo a associação, essa tarefa não envolve apenas as escolas, mas também a família e a Igreja em um único comprometimento na educação: visando a uma geração que esteja preparada e habilitada para aplicar princípios bíblicos em todas as áreas da vida.

Esse modelo de educação, para a associação, está relacionado a uma estratégia para a continuação da crença com base na ampliação da fé que se tem para com o Reino de Deus. Assim, é dever do cristão oferecer uma educação de qualidade, fundamentada em princípios bíblicos, preparando-os para cumprir o propósito de Deus para as gerações futuras.

O Colégio Shalom é um exemplo desse modelo, pois desenvolve:

Educação Por Princípios, os primeiros conceitos se encontram no documento História Cristã da Constituição dos EUA (1960), de Verna Hall. Em 1965, Rosalie Slater publicou Ensinando e Aprendendo a História Cristã Americana (T\&L), em que enfatiza a importância do estudo bíblico na escola, segundo o Principle Approach (Principal Conteúdo). Após a criação da F.A.C.E - Fundação para a Educação Cristã Americana - a Educação por Princípios cresceu e se difundiu. Atualmente, um dos estudiosos mais aplica- 
dos é Paul Jehle, que foi instrutor de Cida Mattar, responsável pela introdução do sistema de ensino por princípios no Brasil, em 1988 (COLÉGIO SHALOM, s/d, s/p).

A partir do exemplo citado, pode-se relacionar o modelo educacional com base religiosa proposto hoje com a Ordem Jesuítica. Pedagogicamente, as propostas remetem ao Ratio Studiorum, por se tratar de um sistema restrito a um único objetivo. Afinal, para a filiação à AECEP das escolas, não basta que elas sejam cristãs. Como nos tempos da Ordem Jesuítica:

A instituição de colégios para estudantes não pertencentes à Ordem não entrava no plano primitivo de Inácio, mas bem depressa se lhe impôs como uma necessidade de quase indeclinável e um instrumento eficaz de renovação cristã muito em harmonia com as suas falhas finalidades e com a inclinação espontânea de Inácio (FRANCA, 1952, p. 7).

O Instituto Adventista, adversamente, apesar de ter princípios cristãos em sua proposta metodológica e filosófica de ensino, apresenta seus objetivos de forma mais generalizada, focalizando o cidadão social e profissional.

Existe, portanto, a necessidade de diferenciar o Ensino Religioso de um ensino para a cidadania. Há uma grande diferença entre ensinar religião e propor uma religião. A partir dos exemplos, percebe-se que as algumas propostas educacionais não reconhecem e não esclarecem os limites entre uma e outra proposta. Fica evidente que algumas das propostas observadas estão mais preocupadas na continuidade (perpetuação) de suas filosofias do que propriamente na formação de um indivíduo socialmente capaz.

\section{Reflexões sobre três modelos educacionais e seus aspectos}

As questões e as preocupações pedagógicas e sociais resumem-se, grosso modo, a duas questões: o que garante que certa filosofia religiosa é a melhor opção para educar? Como garantir o direito de escolha de um indivíduo, diante de doutrinas e da imposição de certas normas de conduta?

Passos (2007) mostra três modelos de Ensino Religioso aplicado às escolas, conforme o Quadro.

Com base nos dois primeiros exemplos e relacionando-os com a Ordem Jesuítica, é possível supor que o modelo catequético com o intuito de instaurar uma única religião, em um sistema doutrinador tradicional - com vistas à expansão da religião e da Igreja, a qualquer custo -, é o que ainda prevalece quando se trata das escolas associadas ao cristianismo. O Ensino Religioso passa, segundo esses exemplos, a disciplina integrante principal na formação básica do cidadão. 
Quadro - Modelos de Ensino Religioso.

\begin{tabular}{|c|c|c|c|}
\hline Aspecto & Catequético & Teológico & $\begin{array}{l}\text { Ciências / Religião } \\
\text { Antropológica }\end{array}$ \\
\hline Cosmovisão & Unirreligiosa & $\begin{array}{c}\text { Plurirreligiosa } \\
\text { ecumênica }\end{array}$ & Transreligiosa \\
\hline Contexto pluralístico & $\begin{array}{c}\text { União entre Estado e } \\
\text { Igreja }\end{array}$ & Sociedade secularizada & Sociedade secularizada \\
\hline Fonte & Conteúdo doutrinado & $\begin{array}{c}\text { Antropologia / } \\
\text { Pluralismo }\end{array}$ & Estudo da religião \\
\hline Método & Doutrina & Indutivos & Indutivos \\
\hline Afinidade & Tradicional & Escola Nova & Epistemologia atual \\
\hline Objetivo & Expansão da Igreja & $\begin{array}{c}\text { Formação religiosa do } \\
\text { cidadão }\end{array}$ & Educação do cidadão \\
\hline Responsabilidade & Confissões religiosas & Confissões religiosas & Comunidade científica \\
\hline Riscos & $\begin{array}{l}\text { Proselitismo e } \\
\text { intolerância }\end{array}$ & Catequese disfarçada & Neutralidade científica \\
\hline
\end{tabular}

Fonte: Passos (2007).

Para que não haja essa padronização do ensino, considera-se um modelo inter-religioso ou pluralista, conforme apresentado no último exemplo do Quadro: Ciências/Religião Antropológica. Nesse modelo, o Ensino Religioso é concebido de forma abrangente e variável conforme as opções e as modalidades religiosas; as instruções são voltadas ao cotidiano, não pressupondo que o educando se identifique com algum credo ou religião, mas se fundamente nas informações antropológicas.

Essa abordagem, relacionada à Antropologia, concebe o sentimento religioso como expressão de necessidades do educando e ancora-se na sua percepção de mundo, sob seu viés cultural.

Em relação aos conteúdos e à almejada interdisciplinaridade, no Ensino Religioso, para Steil (1996, p. 50-52 apud DANTAS, 2004, p. 118), são necessárias a garantia à diversidade de ensino e a reflexão sobre a cidadania:

O ensino religioso pluralista deve apresentar uma visão positiva da diversidade religiosa, situando-a como parte de um contexto democrático onde a liberdade de pensamento e de credo pode se expressar. Nesse sentido, deve estimular o diálogo e a interação entre os preconceitos e revelar seus pontos de convergência [...]. Uma perspectiva histórica e sociológica das religiões pode ser importante para desvendar as razões de muitos conflitos que dividem grupos e pessoas. Muitos preconceitos e discriminações estão relacionados com fatos históricos que, uma vez analisados, permitiriam construir uma outra imagem dos grupos e pessoas que estão diretamente relacionados a eles. A educação religiosa deve buscar 
ainda internalizar nos alunos uma ética que deve ação e comportamento dentro de um mundo plurireligiosa. Uma ética que se deve traduzir em práticas e atitudes apropriadas para uma convivência humana numa sociedade pluralista. Ou seja: que os impulsionem a comportar-se em consonância com a afirmação da liberdade religiosa e respeito a outras religiões diferentes da sua.

Para essa sistematização do ensino, é necessário contar com a abolição do fundamentalismo religioso nas escolas. Sendo assim, esse modelo de ensino é dos mais relevantes, por permitir e instigar questionamentos a respeito da real necessidade do Ensino Religioso no currículo escolar. Há nesse modelo uma confiança em que:

[...] o fator "religioso" há de ser procurado não nas religiões tidas comumente como tais, mas naquilo que é comum a todos os homens e mulheres seriamente empenhados em realizar o sentido último da existência. Ou seja, prefere-se partir hoje não de uma suposta "posse", mas da "busca" (GRUEN, 1995, p. 24 apud DANTAS, 2004, p. 121).

Um Ensino Religioso Antropológico, relacionando ciência e religião, é, sob certa perspectiva, plausível por proporcionar o questionamento e o verdadeiro direito à escolha antes de qualquer imposição de credo.

Nessa prática de ensino, parece haver uma recusa à religiosidade fechada; há uma concepção abrangente do alcance e das necessidades relacionados às experiências e à existência do homem. A religião, afinal, também é vista como uma maneira concreta de o homem conhecer-se e até mesmo constituir-se.

As reflexões que se fazem diante desse modelo e suas respectivas práticas pedagógicas, relacionadas à disciplina religiosa, mostram uma notável diferença: o respeito tanto para com o aluno, que não possui uma religião, quanto para com aquele que a tem. A simples consideração pela liberdade de escolha religiosa, mesmo que não seja o caso da grande maioria, responde a uma das indagações realizadas, visto que a religião integra, sob esse modelo, o currículo, mas garante o direito à escolha e a questionamentos.

Essa última proposta analisada visa buscar a reflexão e o debate diante da educação uniformizadora, como a catequização, no caso dos jesuítas. Procura, assim, levar à escola uma formação crítica em um cenário pluralista, tanto cultural quanto religioso, englobando professores, dirigentes de escola, alunos e seus familiares. Os educadores são todos tomados por um posicionamento receptivo às diferentes crenças, seja ele pedagogo, seja ela especialista de área.

Essa proposta visa ainda à inter-religião: uma confiança na busca pelas práticas inclusivas. Não importa, portanto, se há ou não uma crença em uma fé específica, nem a cor da pele, nem a descendência, nem o gênero, nem a orientação sexual ou quaisquer determinantes culturais. 
Se o Ensino Religioso se fizer necessário e importante, que se atente para que seu espaço seja para a contribuição na melhoria da educação pela formação crítica, pelo respeito ao próximo e pela formação de cidadãos.

\section{Ensino Religioso como componente curricular: métodos e abordagens}

Convém apontar algumas propostas de Ensino Religioso que se destacam hoje no âmbito das escolas de Ensino Fundamental:

1- Ensino Religioso confessional: em que cada representação religiosa oficial tem sua expressão litúrgica e doutrinária, marginalizando outras expressões minoritárias. Essa proposta está ancorada nas tradições do cristianismo, pois os alunos são sempre visados como potenciais fiéis.

2 - Ensino Religioso ecumênico: no qual a ênfase está nas posturas éticas, buscando princípios doutrinários e litúrgicos afins. O grupo religioso de maior expressão exerce maior influência sobre os demais.

3 - Ensino Religioso fenomenológico: nessa proposta, há uma abordagem antropológica, observando-se diversas manifestações religiosas e culturais. O estudo das religiões é feito pela comparação entre as diferentes manifestações de fé ou pelo resgate da história das religiões.

Algumas observações podem ser feitas a respeito dessas propostas: o ensino confessional em um âmbito público, à medida que marginaliza as minorias e exerce profundo controle, pelas confissões, sobre as atividades dos alunos, pode ser encarado como uma agressão ao direito da liberdade e como manifestação explícita de uma força política de manipulação. No ensino ecumênico, por mais que haja um ideal de conduta ética, a hegemonia do grupo majoritário acaba, em uma sociedade como a brasileira, sempre por abafar as diferenças e homogeneizar os indivíduos. Quanto ao ensino fenomenológico, o empecilho está na formação cultural, social e profissional do professor, o qual deveria manifestar-se com a (im)possível neutralidade de influência proselitista sobre seus alunos.

Independentemente do sistema de ensino adotado, uma reflexão é indispensável: o Ensino Religioso como matéria curricular dispõe da escola não apenas como um espaço de conhecimento e aprendizado, mas também potencializa seu viés de instrumento de disciplinarização, regimentação, ordenação e controle.

É necessário, em qualquer investimento no processo educacional, tomar consciência de que as experiências do aluno, suas vivências, sua formação cultural, seu ambiente de vida, sua constituição socio-histórica, enfim, são indispensáveis. A construção de um conhecimento sustentável faz-se mediante e a partir da realidade cotidiana do aluno. É preciso, dessa forma, considerar as ideias vygotskyanas. 
Embora se torne um empreendimento ainda mais delicado, quando se fala de Ensino Religioso, por tratar das diferentes formações socio-históricas, cada qual ao mesmo tempo demasiadamente abrangentes e particulares, o respeito aos valores dos alunos é fundamental para que eles saibam, antes de tudo, também respeitar e conviver socialmente. É desse convívio, afinal, que se notam os aprendizados de sucesso.

É preciso admitir o desafio de uma prática pedagógica que trabalhe pela integração das diversas realidades de crenças, de experiências e de valores culturais: uma premissa básica àqueles que desejem fundamentar o Ensino Religioso em uma pedagogia crítica. Metaforicamente, todas as experiências são bagagem que o educando carrega para dentro da escola e com as quais ela deve trabalhar para lhe fornecer todos os demais subsídios que se fizerem necessários à sua viagem. Qualquer sistema educacional que viole essa bagagem é uma violação à história do aluno e pode, portanto, constituir-se antes como empecilho do que como passaporte ao seu desenvolvimento cognitivo e social. As doutrinas, bem como a disciplina exigida em sala, são, sob essa perspectiva, relações de poder que se instauram na sala de aula e que, quando são inevitáveis, também não devem tolher, banalizar ou relevar as menores manifestações de resistência.

Analisando os breves aspectos históricos, a intenção da presença da Igreja na escola não tinha o intuito de fomentar a ampliação de conhecimento e a promoção da consciência crítica do homem; ao contrário, a primeira tarefa era voltada à conversão dos povos considerados sem religião ao catolicismo, combatendo, segundo a ordem, toda manifestação de heresia. Não havia espaços para as palavras ou os atos de resistência ou para doutrinas que conflitassem os dogmas da Igreja Católica.

Ao entender a fundação da ordem jesuítica, é possível olhar para a padronização imposta e estabelecida por regras direcionadas para a disciplinarização da mente, sobretudo com fins de catequização, de doutrinação ao mero exercício de instrução, instruindo para se alcançar o objetivo de convertê-lo em determinada crença (no caso dos jesuítas, ao cristianismo).

A ordem - disciplina - foi representada por discípulos de Inácio de Loiola e teve importantes repercussões sociais, sobretudo à medida que se lançaram aos primeiros momentos da associação entre escola e Igreja. Apenas casos extremos de resistência eram transferidos ao papa. A origem da Ordem Jesuítica pode ser lida, portanto, como legitimação das relações que se estabeleciam.

Não se deve, contudo, cair no erro de atribuir aos jesuítas que investiram seu trabalho nas missões entre os séculos XVI e XVIII toda espécie de culpa sobre as condições sociais atuais do Brasil.

A relação entre a escola e a Igreja, no século XVI, não teve em vista o respeito às crenças e culturas dos povos gentis. A imposição de normas de conduta e de práticas de culto reinou, mas, na escala hierárquica, os jesuítas também 
pouco ou nada podiam (ou conseguiam) se manifestar, também pela própria formação a que eram submetidos. Nem se pode afirmar, categoricamente, que as pretensões todas da Igreja ou seus alcances na sociedade tenham sido conscientemente planejados. Uma perspectiva de ensino que prioriza a cultura já estabelecida e considera a formação social do homem, como já mencionado, é a metodologia socio-histórica de Vygotsky. Para esse psicólogo, a relação entre o desenvolvimento e a aprendizagem está diretamente relacionada com o ambiente sociocultural (OLIVEIRA, 1997).

Nas palavras de Oliveira (1997, p. 62):

O processo de ensino e aprendizagem na escola deve ser construído, então, tomando como ponto de partida o nível de desenvolvimento real da criança num dado momento e com relação a um determinado conteúdo a ser desenvolvido.

Ao se referir ao Ensino Religioso, essa proposta de se considerar o contexto histórico da educação e o conhecimento prévio do educando não pode ser diferente. É preciso considerar que o educando e o educador levam à escola sua fé, seus valores e suas crenças.

Para a prática desse pensamento de respeitar a crença já estabelecida pelo educando, assim como pelo educador, diante de inúmeras culturas, crenças e fé, cria-se uma indagação de como construir um Ensino Religioso sem exclusão social. A questão desemboca em como lidar, diante das variedades de culturas e crenças, com um Ensino Religioso que não promova a exclusão social. Passos (2007, p. 27) lembra que:

[...] a atitude de ensino se dá a partir de conteúdos a serem difundidos; conteúdos que podem vir do senso comum, de tradições religiosas ou de acúmulos das pesquisas científicas, no caso, da ciência. De qualquer forma, há algo a ser ensinado aos educandos, independente da coerência e consistência dos conteúdos a serem propagados e também do modo como ensina.

Para Passos (2007), há sempre algo a ensinar, há sempre o que se transferir e, acima de tudo, a aprender. A globalização, o avanço da tecnologia e as condições em que as sociedades vivem hoje modificaram/modificam muitos valores de uma geração a outra.

A concessão de um espaço para o Ensino Religioso dentro da escola pode se tornar um pretexto de uma reflexão das ações dos cidadãos na sociedade e, eventualmente, de uma problematização e/ou resgate de valores. Não há, sob as visões de Passos, Freire e Vygotsky, espaço para a discussão ou a problematização de qualquer crença. 
À medida que vier para polemizar questões de cunho social, o Ensino Religioso pode, portanto, atender a uma demanda atual da escola: um intervalo, um tempo de contato e/ou a troca de valores e de experiências. Há, dessa forma, um local que pode ser preenchido pelo Ensino Religioso se este não se ativer à defesa de embate de credos.

\section{Considerações finais}

Este artigo teve como principal objetivo apresentar alguns modelos de Ensino Religioso existentes em escolas particulares, como a Associação de Escolas Cristãs de Educação por Princípios, o Colégio Shalom e o Instituto Adventista.

Realizou-se a demonstração de diferentes metodologias presentes nas escolas privadas bem como alguns exemplos retirados das próprias escolas. Diante disso, o artigo contribuiu como fonte de conhecimento para reconhecer que existem diversos modelos de Ensino Religioso e que é de responsabilidade de cada escola adotar o que considera melhor para seu público-alvo.

$\mathrm{O}$ artigo apresentou ainda um modelo de ensino fundamentado na Ciência/Religião que hoje é visto como Ciência da Religião e considerado uma linha de ensino importante para as escolas. Entretanto, o material apresentado neste artigo contribui para uma reflexão de que a metodologia Ciência/Religião considerada hoje como um modelo ideal para a aplicabilidade do Ensino Religioso nas escolas não se aplica às escolas particulares, as quais obtêm objetivos específicos (confessionais), destinados a determinado público. Dessa forma, além de trazer uma demonstração de diversos modelos existentes para a aplicabilidade do Ensino Religioso, este artigo apresentou uma reflexão sobre a importância da diversidade desses modelos de ensino, bem como a compreensão de que as escolas particulares se mantêm no direito de continuar suas propostas de ensino pautada em uma metodologia confessional.

Recebido em: 05/05/2019

Revisado pelo autor em: 24/06/2019 Aceito para publicação em: 30/06/2019

\section{Notas}

1 Doutoranda em Ciência da Religião pela Pontifícia Universidade Católica de São Paulo (PUC-SP). Mestre em Letras-Linguagem e Identidade pela Universidade Federal do Acre. Especialista em Gestão Educacional pela Universidade Anhanguera-UNIDERP. Graduada em Pedagogia pela Pontifícia Universidade Católica de Campinas (PUC-Campinas). E-mail: elainehonoratocap@hotmail.com 


\section{Referências}

AECEP - Associação de Escolas Cristãs de Educação por Princípios. Fundamento essencial para uma nação cristã. s.d. Disponível em: https:/ /www. aecep.org.br/aecep/sobre-educacao. Acesso em: 11 jan. 2019.

BOWKER, John. Para entender as religiões: as grandes religiões mundiais explicadas por meio de uma combinação perfeita de textos e imagens. Tradução de Cássio de Arantes de Leite. São Paulo: Ática, 2000.

CENTRO EDUCACIONAL SHALLON. Educação por Princípios. s.d. Disponível em: http://portalshalom.com.br/educacao-por-principios. Acesso em: 25 jan. 2019.

DANTAS, Douglas Cabral. O ensino religioso escolar: modelos teóricos e sua contribuição à formação cultural ética e cidadã. Horizonte, Belo Horizonte, v. 2, n. 4, p. 112-124, 2004. Disponível em: http://periodicos.pucminas.br/index. php/horizonte/article/view/583/614. Acesso em: 18 jan. 2019.

FRANCA, Leonel. O método pedagógico dos jesuíta: o Ratio Studorium. Rio de Janeiro: Agir, 1952.

IASP - Instituto Adventista São Paulo. Nossos objetivos. Disponível em: https://www.educacaoadventista.org.br/ensino/internatos/. Acesso em: 25 jan. 2019.

JUNQUEIRA, Sérgio Azevedo. Ciência da Religião aplicada ao ensino religioso. Compêndio de Ciência de Ciência da Religião. São Paulo: Paulinas/ Paulus, 2013.

OLIVEIRA, Maria Kohl de. Vygotsky: aprendizado e desenvolvimento: um processo sócio-histórico. São Paulo: Scipione, 1997.

PASSOS, João Décio. Ensino religioso: construção de uma proposta. São Paulo: Paulinas, 2007. 